\title{
Unique patterns of cardiogenic and fibrotic gene expression in rat cardiac fibroblasts
}

\author{
Kittipong Tachampa1(D) and Tuempong Wongtawan ${ }^{2,3}$ (D) \\ 1. Department of Physiology, Faculty of Veterinary Science, Chulalongkorn University, Henri-Dunant Rd, Pathumwan, \\ Bangkok, 10330, Thailand; 2. Akkhraratchakumari Veterinary College, Walailak University, Tha Sala, Nakhon Si \\ Thammarat, 80160, Thailand; 3. Laboratory of Cellular Biomedicine, Faculty of Veterinary Science, Mahidol University, \\ Salaya, Puttamonthon, Nakhon Pathom, 73170, Thailand. \\ Corresponding author: Tuempong Wongtawan, e-mail: tuempong.wo@mail.wu.ac.th \\ Co-author: KT: kittipong.t@chula.ac.th \\ Received: 11-02-2020, Accepted: 02-07-2020, Published online: 26-08-2020
}

doi: www.doi.org/10.14202/vetworld.2020.1697-1708 How to cite this article: Tachampa K, Wongtawan T (2020) Unique patterns of cardiogenic and fibrotic gene expression in rat cardiac fibroblasts, Veterinary World, 13(8): 1697-1708.

\begin{abstract}
Background and Aim: Cardiac fibroblasts are important for both normal and pathological states of the heart, but the knowledge in cell physiology and genomics is still poorly understood. The aims of the present study were; first, to investigate the expression of cardiac and fibrotic genes in rat cardiac fibroblasts compared to cardiomyocytes and other fibroblasts (skin and muscle fibroblasts), second, to examine the in vitro effect of serum concentration on fibroblast gene expression. The findings can potentially be applied in ischemia/reperfusion models.
\end{abstract}

Materials and Methods: Rat cardiac fibroblasts were collected and cultured in different conditions, and their gene expression (21 cardiogenic genes and 16 fibrotic genes) was compared with cardiomyocytes and other fibroblasts using comparative quantitative polymerase chain reaction. We also mimicked myocardial ischemia/reperfusion by depleting and then adding a serum into the culture in conventional culture $(10 \%$ serum).

Results: Cardiac fibroblasts expressed most of the cardiogenic genes, but their expression levels were significantly lower than in cardiomyocytes, while almost all fibrotic genes in the cardiac fibroblasts were significantly more highly expressed than in cardiomyocytes, except matrix metallopeptidase 9 ( $\mathrm{Mmp} 9$ ) which also had greater expression in other fibroblasts. After mimicking cardiac ischemia and reperfusion in vitro by starving and then adding a serum into the cardiac fibroblast culture, the results revealed that $M m p 9$ expression was significantly increased ( $>30$ times) after increasing but not reducing the serum in the culture. The expression of most cardiogenic and fibrotic genes in cardiac fibroblasts tended to decrease after increasing the serum in the culture. These changes were specific to cardiac fibroblasts but no other fibroblasts.

Conclusion: Cardiac fibroblasts have a distinct pattern of gene expression from other fibroblasts and cardiomyocytes. They are also sensitive to high serum concentration but not affected by serum depletion, suggesting that the process of developing cardiac fibrosis might be stimulated by reperfusion or overcirculation rather than ischemia. The cell starvation followed the adding of serum may serve as a useful model to study cardiac fibrosis cause by the change of blood flow.

Keywords: cardiac fibroblasts, cardiomyocytes, gene expression, in vitro model, ischemia, reperfusion.

\section{Introduction}

The heart consists not only of cardiomyocytes, but cardiac fibroblasts are also a major component of heart tissue. They take up over $60 \%$ of the total number of cells, or approximately $30 \%$ of the heart tissue, in adult rats and humans [1-4]. It is believed that cardiac fibroblasts have an important role in the development, structural integrity, normal functioning (such as cell signaling and electrophysiology), pathological states, and remodeling of the heart [5-8]. Fibroblasts, the mesenchymal origin cells that are widely distributed in most tissues, produce components of the extracellular matrix (ECM) such as collagen, and glycosaminoglycans and can be activated by pro-inflammatory

Copyright: Tachampa and Wongtawan. Open Access. This article is distributed under the terms of the Creative Commons Attribution 4.0 International License (http://creativecommons.org/licenses/ by/4.0/), which permits unrestricted use, distribution, and reproduction in any medium, provided you give appropriate credit to the original author(s) and the source, provide a link to the Creative Commons license, and indicate if changes were made. The Creative Commons Public Domain Dedication waiver (http:// creativecommons.org/publicdomain/zero/1.0/) applies to the data made available in this article, unless otherwise stated. cytokines and growth factors causing tissue fibrosis [9]. Fibrosis (also known as scar tissue) is the connective tissue deposition that occurs after tissue injury as part of normal healing, but if the process is excessive, it can cause organ abnormalities [5]. Cardiac fibrosis is the imbalance of ECM production and degradation, contributing to cardiac dysfunction and death, usually due to myocardial infarction or heart attack [7]. It is wellknown that heart disease is the leading cause of death in humans and dogs. Therefore, studying the biology and physiology of fibroblasts is important for understanding the disease and discovering novel treatments for tissue fibrosis, including cardiac fibrosis and myocardial injury.

Arecent report comparing the expression of mouse cardiac fibroblasts to heart tissues and tail fibroblasts suggested that mouse cardiac fibroblasts are unique, and express some cardiac markers such as Gata4, $M e f 2 c$, and Tbx20 [10,11]. However, using heart tissue in the experiment had disadvantages. Namely, heart tissue contains too many cell types, including cardiomyocytes, endothelium, fibroblasts, and nerve cells. 
Therefore, the direct comparison of gene expression between cardiac fibroblasts and cardiomyocytes cannot be made using heart tissue. Moreover, the knowledge of property and function of cardiac fibroblasts is still limited. The rat is a valuable animal research model for investigating cardiovascular diseases. Many breeds and experimental procedures have been developed for disease studies, including myocardial infarction (MI), hypertension, cardiac hypertrophy, heart failure, and stroke [12]. The rat and primate cardiac fibroblasts are similar in biology and function and have been widely used to investigate both physiology and processes of cardiac diseases as a study model for human heart disease $[5,6,8,13]$.

The aims of the present study were; first, to investigate the expression of cardiac and fibrotic genes in rat cardiac fibroblasts compared to cardiomyocytes and other fibroblasts (skin and muscle fibroblasts), second, to examine the in vitro effect of serum concentration on fibroblast gene expression. The findings can potentially be applied in ischemia/reperfusion models.

\section{Materials and Methods \\ Ethical approval}

This research project was approved by the Animal Care and Use Committee of Mahidol University (Approval Number: MUVS-2015-43). Rats were obtained from the National Laboratory Animal Centre, Mahidol University. In total, six Sprague Dawley rats (Rattus norvegicus) weighing between 250 and $300 \mathrm{~g}$ were used. The first group of three rats was used to collect cardiomyocytes and the remainings were used to obtain cardiac fibroblasts.

\section{Experimental plan}

The expression of cardiac and fibrotic genes was examined through three different experimental studies. In the first study, a comparison of gene expression between cardiac fibroblasts and cardiomyocytes was performed, followed by a comparison of gene expression among fibroblasts from different sources: Skin, skeletal muscle, and heart. In the second study, the effects of serum concentration on gene expression in cardiac, skin, and muscle fibroblasts were analyzed and compared. In the last experiment, we investigated gene expression in fibroblasts in an experimentally-simulated myocardial ischemia/reperfusion using an in vitro culture system. The procedure involved initial starvation by providing no serum to the culture, then subsequently adding a serum to the culture.

\section{Single cardiac myocyte isolation}

Ventricular myocytes were isolated using procedures modified from a previous study [14]. Rats were first anesthetized by pentobarbital sodium (Nembutal, CEVA, Belgium) at a dosage of $40 \mathrm{mg} / \mathrm{kg}$, injected intraperitoneally. The thorax was surgically opened, then the heart was detached and immediately transferred to a dish containing $10 \mathrm{~mL}$ of perfusion buffer
(133.5 mM NaCl, $4 \mathrm{mM} \mathrm{KCl}, 1.2 \mathrm{mM} \mathrm{NaH}_{2} \mathrm{PO}_{4}$, $10 \mathrm{mM}$ HEPES, $1.2 \mathrm{mM} \mathrm{MgSO}{ }_{4}, 33.33 \mathrm{mM}^{2}$ dextrose and $0.1 \% \mathrm{BSA}$ ). Thereafter, the heart was cannulated and perfused with perfusion buffer for $4 \mathrm{~min}$ (the flow rate was $3 \mathrm{~mL} / \mathrm{min}$ ) to remove the remaining blood clot within the chamber. Then, cardiomyocyte digestion buffer containing $0.05 \%$ collagenase type II (Merck, MO, USA) and $0.02 \%$ protease IV (Merck, Missouri, USA) was perfused for $10 \mathrm{~min}$. The obtained cell suspension was transferred into a $15-\mathrm{mL}$ tube before inactivating proteases by adding $2.5 \mathrm{~mL}$ of myocyte stopping buffer containing serum. To enrich the cell suspension with viable cardiomyocytes and to remove large, undigested chunks of tissue, dispersed cardiomyocytes were filtered through a nylon mesh (cell strainer) with a hole size of 200-300 $\mu \mathrm{m}$ (BD Bioscience, CA, USA). Samples were centrifuged at $5.41 \times \mathrm{g}$ for $1.5 \mathrm{~min}$, and then the supernatants were removed. Cell pellets were kept at $-80^{\circ} \mathrm{C}$ for further RNA extraction.

\section{Fibroblast isolation and culture}

The rats were euthanized by intraperitoneal injection of sodium pentobarbital $(150 \mathrm{mg} / \mathrm{kg})$. Fibroblasts were isolated from three tissue types: Skin (ear), muscle (hind limb), and heart (ventricle). Tissues of the same type from the three rats were mixed together. The tissues were cut, washed in phosphate-buffered saline (PBS), and minced in a $250 \mu \mathrm{L}$ drop of $0.025 \%$ collagenase type I (Sigma-Aldrich, MO, USA) in a $100 \mathrm{~cm}$ tissue culture plate. The small pieces of tissue were transferred into a $50 \mathrm{~mL}$ sterile conical tube (Falcon ${ }^{\circledR}$, Corning, NY, USA) containing $2.5 \mathrm{~mL}$ of $0.025 \%$ collagenase type I and incubated at $37^{\circ} \mathrm{C}$ for $20 \mathrm{~min}$ for the skin tissue, $35 \mathrm{~min}$ for the muscle tissue, and $50 \mathrm{~min}$ for the heart tissue. Then, $5 \mathrm{~mL}$ of $0.25 \%$ trypsin-EDTA (ThermoFisher Scientific, MA, USA) were added and incubated at $37^{\circ} \mathrm{C}$ for $10 \mathrm{~min}$. Thereafter, $5 \mathrm{~mL}$ of PBS was added, and the tissues were vortexed briefly before being centrifuged at $1000 \times \mathrm{g}$ for $5 \mathrm{~min}$. Then, the sediment was resuspended with $5 \mathrm{~mL}$ of culture media containing Dulbecco's Modified Eagle Medium (DMEM) with high glucose (Thermo Fisher Scientific, MA, USA), $10 \%$ fetal bovine serum (FBS) (Sigma-Aldrich, MO, USA), and antibiotic-antimycotic solution (Thermo Fisher Scientific, MA, USA). The cells were introduced into a $10-\mathrm{cm}$ cell culture dish and incubated for 2 days at $37^{\circ} \mathrm{C}$ in a $5 \% \mathrm{CO}_{2}$ incubator (Heal Force, Shanghai, China).

\section{Comparing the effect of serum concentration on gene expression in cardiac fibroblasts}

Cardiac fibroblasts (the $3^{\text {rd }}$ passage) were cultured in three groups; a culture medium with varied serum concentration, $5 \%, 10 \%$, or $20 \%$ FBS. Each group was cultured in a separated, six-well plate. Each plate contained the six replications of each treatment. They were cultured for a week before the analysis of gene expression. 


\section{Serum starvation and adding serum}

In this study, serum starvation was used as an in vitro model of ischemia, while adding serum after starvation was used as in vitro model of reperfusion.

Cardiac fibroblast culture was divided into four groups (four six-well plates). They were cultured in DMEM plus 10\% FBS for 3 days. The first group was cultured with DMEM plus $10 \%$ FBS until day 8 , while others were initially starved for $24 \mathrm{~h}$ by culturing in non-serum DMEM medium. After the starvation, one group of the cultures was collected for RNA collection, and the other two groups received serum with either $10 \%$ or $20 \% \mathrm{FBS}$ and continued the culture for 4 days before RNA extraction.

\section{Comparative quantification of gene expression}

RNA extraction was performed using QuickRNA $^{\text {TM }}$ MiniPrep (Zymo Research, CA, USA). The RNA concentration was measured using a Nanodrop 2000 machine (Thermo Fisher Scientific, MA, USA). The extracted RNAs were converted to cDNAs by Superscript VILO cDNA synthesis kit (Thermo Fisher Scientific, MA, USA). These cDNAs were used as a template for quantitative polymerase chain reaction (qPCR).

Real-time qPCR was performed using KAPA SYBR Fast qPCR master mix (2x) universal (KAPA Biosystem, MA, USA) and Rotor-Gene Q PCR machine (Qiagen, Hilden, Germany). The PCR reaction contained $10 \mu \mathrm{L}$ of the master mix, $0.4 \mu \mathrm{L}$ of each primer, and $1 \mu \mathrm{g}$ of cDNA and was filled with PCRgrade water to $20 \mu \mathrm{L}$. Comparative gene expressions were analyzed using Rotor-Gene Q software (Qiagen, Hilden, Germany). The PCR program was set similar to a previous publication [15]: Enzyme activation at $95^{\circ} \mathrm{C}$ for $3 \mathrm{~min}$, denaturation at $95^{\circ} \mathrm{C}$ for $3 \mathrm{~s}$, and Annealing/extension/data acquisitions at $60^{\circ} \mathrm{C}$ for 30 $\mathrm{s}$, then performed for 35 cycles. Melt curve analysis was performed to confirm the specific product; the program for melt curve analysis was increasing temperature from $60^{\circ} \mathrm{C}$ to $99^{\circ} \mathrm{C}$ using speed rate $4 \mathrm{~s} / 1^{\circ} \mathrm{C}$. The geometric averaging of two housekeeping genes, glyceraldehyde 3-phosphate dehydrogenase (Gapdh), and actin beta (Actb) was used as a reference gene for normalization [16]. The PCR was done in triplicate.

The 21 cardiogenic genes used in this study were: Myoglobin $(M b)$, T-Box Transcription Factor 20 (TBX20) myosin light chain 2 (Myl2), myosin light chain 3 (Myl3), myosin light chain 7 (Myl7), natriuretic peptide A (Nppa), creatine kinase type $\mathrm{M}$ $(\mathrm{Ckm})$, potassium voltage-gated channel subfamily $\mathrm{Q}$ member 1 (Kcnq1), troponin T2 - cardiac type (Tnnt2), phospholamban $(P l n)$, actinin-alpha 2 (Actn2), ryanodine receptor 2 (Ryr2), NK2 homeobox 5 (Nkx2-5), GATA binding protein 4 (Gata4), adrenoceptor beta 1 (Adrb1), myosin heavy chain 7 (Myh7), transcription factor 21 (Tcf21), heart and neural crest derivatives expressed 2 (Hand2), solute carrier family 8 member A1 (Slc8al), GATA binding protein 6 (Gata6), and Wilms tumor 1 (Wtl).
The 16 fibrotic genes were: Matrix metallopeptidase 9 (Mmp9), collagen type I alpha 2 chain (Colla2) transforming growth factor-beta receptor 1 (Tgfbrl), vinculin $(\mathrm{Vcl})$, connective tissue growth factor (Ctgf), tissue inhibitor of metallopeptidase 1 (Timp1), discoidin domain receptor tyrosine kinase $2(D d r 2)$, vimentin (Vim), platelet-derived growth factor receptor-alpha (Pdgfra), actin-alpha 2 (Acta2), collagen type V alpha 2 chain (Col5a2), hepatocyte growth factor ( $\mathrm{Hgf})$, SMAD family member 2 (Smad2), Thy-1 cell surface antigen (Thyl), Paxillin (Pxn), and Periostin (Postn).

The primer sequences are listed in Table- 1 .

\section{Statistical analysis}

Data are shown as mean \pm Standard Error Mean, and one-way ANOVA with the least significant difference adjustment for multiple comparisons was performed using SPSS software version 21.0 (IBM Corp., NY, USA).

\section{Results}

\section{Cardiogenic and fibrotic gene expression in cardiac fibroblasts compared to cardiomyocytes}

The expressions of cardiogenic genes are shown in Figure-1. From 21 cardiogenic genes, cardiomyocytes expressed all of the markers, whereas cardiac fibroblasts expressed only 16 genes. The expression of Ryr2, Ckm, Nppa, Myl2, and $M b$ was not detected in cardiac fibroblasts.

The expression of most cardiogenic genes (ten of 16 genes) was significantly higher $(p<0.01)$ in cardiomyocytes than in cardiac fibroblasts. The expression of Myl3, Kcnq1, Tnnt2, Pln, and Actn2 in cardiomyocytes was 50 to 660 -fold higher than in cardiac fibroblasts. Nkx2-5, Myl7, Gata4, Adrb1, and Myh7 in cardiomyocytes were expressed 2 to 10 -fold higher than in cardiac fibroblasts. Expression of Tcf21, Tbx20, and Hand 2 was not different $(\mathrm{p}>0.05)$. Conversely, expression of Slc8a1, Gata6, and Wt1 was significantly higher $(\mathrm{p}<0.01)$ in cardiac fibroblasts than in cardiomyocytes.

The expressions of fibrotic genes are shown in Figure-2. Almost all of the fibrotic genes (15 of 16 genes) in cardiac fibroblasts were expressed significantly more than in cardiomyocytes $(\mathrm{p}<0.01)$, except Mmp9. The expression of Postn, Pxn, and Thyl was more than 500-fold higher in cardiac fibroblasts than in cardiomyocytes. The expression of Colla2, Smad2, and $H g f$ in cardiac fibroblasts was approximately 200fold higher than in cardiomyocytes. Col5a2, Acta2, Pdgfra, Vim, Ddr2, Timp1, Ctgf, $V c l$, and Tgfbr1 were expressed 10 to 75 -fold higher in cardiac fibroblasts than in cardiomyocytes. On the other hand, $M m p 9$ expression in cardiomyocytes was 8 -fold higher than in cardiac fibroblasts $(\mathrm{p}<0.01)$.

\section{Comparing gene expression among fibroblasts from different sources}

All cardiogenic genes were significantly more expressed $(\mathrm{p}<0.01)$ in cardiac fibroblasts, compared to muscle and skin fibroblasts (Figure-3). The very high 
Table-1: List of polymerase chain reaction primers.

\begin{tabular}{|c|c|c|c|c|c|c|}
\hline No. & Gene name & Sequence $\left(5^{\prime}->3^{\prime}\right)$ & Template strand & Temp. $\left({ }^{\circ} \mathrm{C}\right)$ & Product size & Group \\
\hline \multirow[t]{2}{*}{1.} & ACTN2 & TGGAATGGATTCGACGCACA & Plus & 60.04 & 238 & Cardiogenic \\
\hline & & CCAGCAATGTCCGACACCAT & Minus & 60.68 & & \\
\hline \multirow[t]{2}{*}{2.} & MYH7 & CTCAGTCATGGCGGATCGAG & Plus & 60.32 & 222 & Cardiogenic \\
\hline & & TTCACAGTCACCGTCTTGCC & Minus & 60.53 & & \\
\hline \multirow[t]{2}{*}{3.} & MYL2 & CCAGAACAGAGACGGCTTCA & Plus & 59.68 & 257 & Cardiogenic \\
\hline & & GCATCTCCCGGACATAGTCG & Minus & 60.04 & & \\
\hline \multirow[t]{2}{*}{4.} & MYL3 & CAGCTGAGCCTCTCAGGAAG & Plus & 59.82 & 203 & Cardiogenic \\
\hline & & GACAGAAAGGGTACCACGGG & Minus & 60.04 & & \\
\hline \multirow[t]{2}{*}{5.} & MYL7 & GTTCTCTCCTGCTGAGGTGG & Plus & 59.75 & 101 & Cardiogenic \\
\hline & & CCCCGTGGGTGATGATGTAG & Minus & 59.89 & & \\
\hline \multirow[t]{2}{*}{6.} & HAND2 & AAGAGGAAGAAAGAGCTGAATGA & Plus & 57.50 & 127 & Cardiogenic \\
\hline & & CCCAGACTCTTCACTGCTTGA & Minus & 59.65 & & \\
\hline \multirow[t]{2}{*}{7.} & $N K X 2-5$ & GGGCGGATAAGAAAGAGCTG & Plus & 58.41 & 110 & Cardiogenic \\
\hline & & CACGCGTGGCTTCCGT & Minus & 60.40 & & \\
\hline \multirow[t]{2}{*}{8.} & $A D R B 1$ & AGACGTGCTATGTGTGACGG & Plus & 60.11 & 294 & Cardiogenic \\
\hline & & ACGTAGAAGGAGACGACGGA & Minus & 60.04 & & \\
\hline \multirow[t]{2}{*}{9.} & NPPA & GCAAACATCAGATCGTGCCC & Plus & 59.90 & 170 & Cardiogenic \\
\hline & & GGTGGTCTAGCAGGTTCTTGAAA & Minus & 60.50 & & \\
\hline \multirow[t]{2}{*}{10.} & RYR2 & TGAAGTCACAGGATCCCAACG & Plus & 60.00 & 151 & Cardiogenic \\
\hline & & AGCCACCATTGGTCCAGTTT & Minus & 59.81 & & \\
\hline \multirow[t]{2}{*}{11.} & KCNQ1 & GCCTCACTCATCCAGACTGC & Plus & 60.46 & 186 & Cardiogenic \\
\hline & & AGGACTCAGCCCGTTATCCT & Minus & 60.03 & & \\
\hline \multirow[t]{2}{*}{12.} & PLN & ACAGAAGCCAAGGCCTCCTAAA & Plus & 61.63 & 213 & Cardiogenic \\
\hline & & GAGGTTCTGGAGGTTCTGACG & Minus & 60.07 & & \\
\hline 13. & SLC8A1 & AACCTCAGTGCCAGACACAT & Plus & 59.23 & 272 & Cardiogenic \\
\hline & & СTCСTATTTCTGGCCTCCGC & Minus & 60.25 & & \\
\hline 14. & $C K M$ & AAGGGTGGAGACGATCTGGA & Plus & 59.96 & 145 & Cardiogenic \\
\hline & & TGTTGAGAGCTTCCACGGAC & Minus & 59.97 & & \\
\hline 15. & $M B$ & ACAGGAAGTCCTCATCAGTCTA & Plus & 57.68 & 240 & Cardiogenic \\
\hline & & TCCAGGTACTTGACCGGGAT & Minus & 59.96 & & \\
\hline 16. & Tnnt2 & AACGACAACCAGAAAGTCTCCA & Plus & 59.83 & 102 & Cardiogenic \\
\hline & & CACAGGCAAGGAACAGAGCTT & Minus & 60.82 & & \\
\hline 17. & Gata4 & TGGCCAGGACTGTCGCTTC & Plus & 62.24 & 235 & Cardiogenic \\
\hline & & CTCCAGAAACTGCAGGAGGG & Minus & 60.04 & & \\
\hline 18. & $T b \times 20$ & TCTTCACAGCAGTCACAGCC & Plus & 60.25 & 130 & Cardiogenic \\
\hline & & AGAACAAGATCTCATTCCСTCTCG & Minus & 59.90 & & \\
\hline 19. & $T c f 21$ & TCAACCTGACTTGGCCCTTT & Plus & 59.44 & 219 & Cardiogenic \\
\hline & & GGGATAGGGAGAGGAGCGAT & Minus & 59.96 & & \\
\hline 20. & Gata6 & CAACGCATGCGGTCTCTACA & Plus & 60.74 & 296 & Cardiogenic \\
\hline & & CAGAGCTGTTACCGGAGCAA & Minus & 60.04 & & \\
\hline 21. & $W t 1$ & CGGAAGCACACTGGTGAGAA & Plus & 60.25 & 219 & Cardiogenic \\
\hline & & CCGACAGCTGAAGGGCTITT & Minus & 60.89 & & \\
\hline 22. & Col5a2 & CTGGAGCTGTTGGGCCATTA & Plus & 60.03 & 187 & Fibrotic \\
\hline & & ATGCCTTGAAGACCTGGTGG & Minus & 59.96 & & \\
\hline 23. & Postn & TGCAAAAAGACACACCTGCAA & Plus & 59.45 & 178 & Fibrotic \\
\hline & & CCGAAGTCAATGGGGCTCTT & Minus & 60.04 & & \\
\hline 24. & $D d r 2$ & GCCAGTTTGGGGAGGTTCAT & Plus & 60.25 & 101 & Fibrotic \\
\hline & & CACCAGGACAGGCTGGTTAG & Minus & 60.04 & & \\
\hline 25. & Pdgfra & AGGCTTGGGGCTCACTITIT & Plus & 60.11 & 132 & Fibrotic \\
\hline & & CTCGGCCCTGTGAGGAGA & Minus & 60.36 & & \\
\hline 26. & Thy 1 & TCCTGCTTTCAGTCTTGCAG & Plus & 58.11 & 127 & Fibrotic \\
\hline & & TCATGCTGGATGGGCAAGTT & Minus & 59.96 & & \\
\hline 27. & Acta2 & GGAGATGGCGTGACTCACAA & Plus & 60.04 & 152 & Fibrotic \\
\hline & & CGCTCAGCAGTAGTCACGAA & Minus & 60.11 & & \\
\hline 28. & Vim & TGCGGCTGCGAGAAAAATTG & Plus & 60.39 & 111 & Fibrotic \\
\hline & & GGTCAAGACGTGCCAGAGAA & Minus & 59.97 & & \\
\hline 29. & $P x n$ & GGAGGAACACGTCTACAGCTTC & Plus & 60.67 & 224 & Fibrotic \\
\hline & & AAATGATTGCTCGTCCCTCCG & Minus & 60.74 & & \\
\hline 30. & $\mathrm{VCl}$ & CCGCGATGCCGGTGTTT & Plus & 61.15 & 261 & Fibrotic \\
\hline & & TGCAAGCATTCTCGACCTTAATA & Minus & 58.23 & & \\
\hline 31. & Ctgf & CTAGCTGCCTACCGACTGG & Plus & 59.26 & 260 & Fibrotic \\
\hline & & GGCTTGGCAATTITAGGCGT & Minus & 59.75 & & \\
\hline 32. & Mmp9 & TCTGCCTGCACCACTAAAGG & Plus & 59.96 & 288 & Fibrotic \\
\hline & & CAGGCTGTACCCTTGGTCTG & Minus & 60.04 & & \\
\hline 33. & Timp1 & ACGCTAGAGCAGATACCACG & Plus & 59.34 & 242 & Fibrotic \\
\hline & & AGCGTCGAATCCTITGAGCA & Minus & 60.04 & & \\
\hline
\end{tabular}


Table-1: (Continued).

\begin{tabular}{|c|c|c|c|c|c|c|}
\hline No. & Gene name & Sequence $\left(5^{\prime}->3^{\prime}\right)$ & Template strand & Temp. $\left({ }^{\circ} \mathrm{C}\right)$ & Product size & Group \\
\hline \multirow[t]{2}{*}{34.} & $\mathrm{Hgf}$ & ACAGCTITTGCCTTCGAGC & Plus & 59.69 & 279 & Fibrotic \\
\hline & & TGTCGGGATATCTTTCCGGC & Minus & 59.61 & & \\
\hline \multirow[t]{2}{*}{35.} & Smad2 & GCCGCCCGAAGGGTAGAT & Plus & 61.55 & 164 & Fibrotic \\
\hline & & TTCTGTTСTССАССАССТGC & Minus & 59.89 & & \\
\hline \multirow[t]{2}{*}{36.} & Tgfbr1 & GGGGCGAAGGCATTACAGT & Plus & 60.08 & 257 & Fibrotic \\
\hline & & TGCTITTCTGTAGTTGGGAGT & Minus & 57.14 & & \\
\hline \multirow[t]{2}{*}{37.} & Colla2 & CTCTGGTGATCCTGGCAAAC & Plus & 58.54 & 235 & Fibrotic \\
\hline & & TTCACCGGGAAGACCCCTTT & Minus & 61.06 & & \\
\hline \multirow[t]{2}{*}{38.} & Gapdh & AGCTCATTTCCTGGTATGACAA & Plus & 57.43 & 258 & Reference \\
\hline & & GGTATTCGAGAGAAGGGAGGG & Minus & 59.04 & & \\
\hline \multirow[t]{2}{*}{39.} & Actb & CCACCAGTTCGCCATGGAT & Plus & 60.08 & 249 & Reference \\
\hline & & CAGTTGGTGACAATGCCGTG & Minus & 60.04 & & \\
\hline
\end{tabular}

$M b=$ Myoglobin, $M y / 2=$ Myosin light chain 2, Myl3=Myosin light chain 3, Myl7=Myosin light chain 7, Nppa=Natriuretic peptide A, Ckm=Creatine kinase type $\mathrm{M}, K c n q 1=$ Potassium voltage-gated channel subfamily Q member 1 , Tnnt2=Troponin T2 - cardiac type, PIn=Phospholamban, Actn2=Actinin alpha 2, Ryr2=Ryanodine receptor 2, Nkx2-5=NK2 homeobox 5, Gata4=GATA binding protein 4, Adrb1=Adrenoceptor beta 1, Tcf21=Transcription factor 21, Hand2=Heart and neural crest derivatives expressed 2, S/c8a1=Solute carrier family 8 member A1, Gata6=GATA binding protein 6 , Wt $1=$ Wilms tumor 1

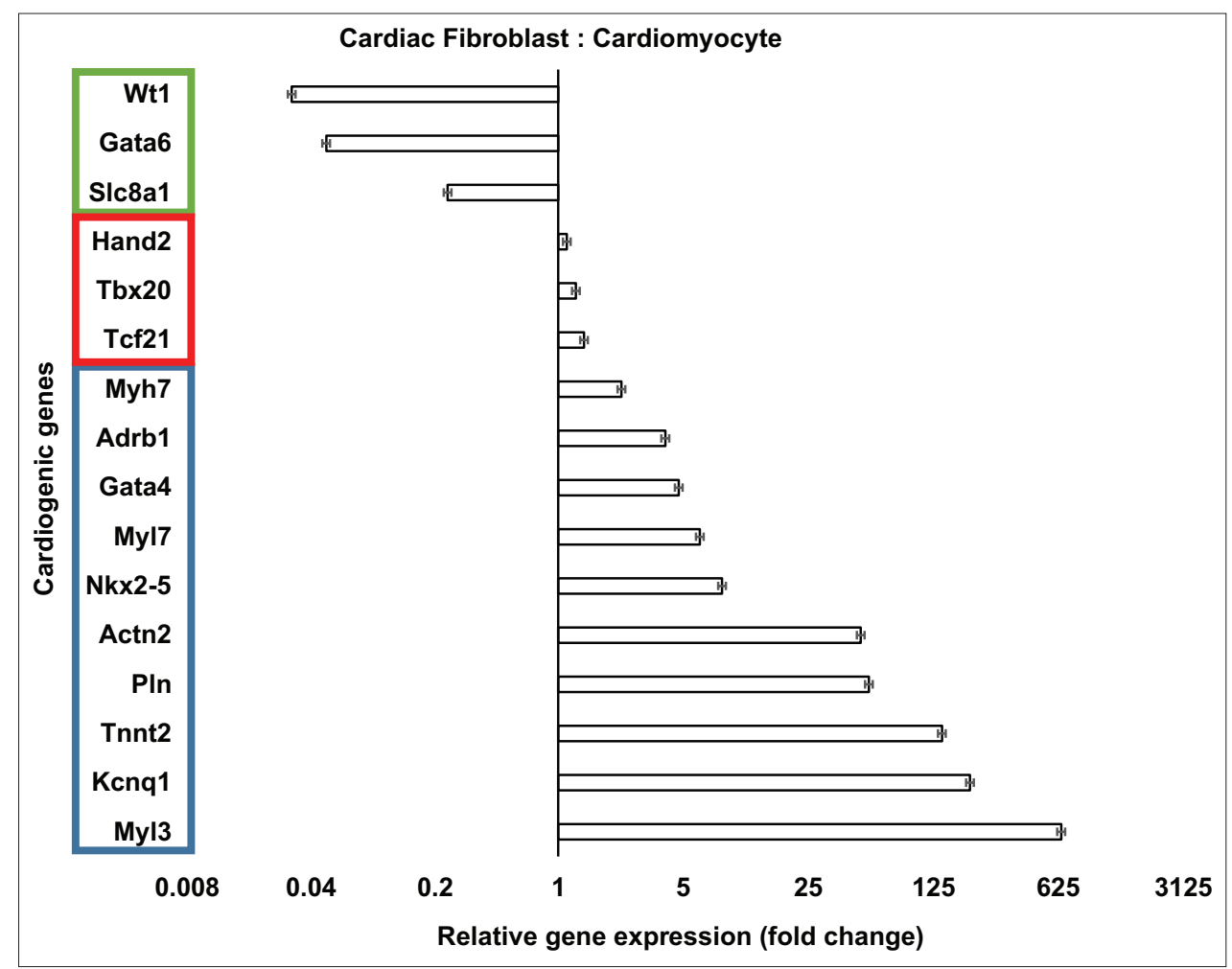

Figure-1: Expression of cardiogenic genes in cardiomyocytes compared to cardiac fibroblasts. Ten genes (in the blue rectangle) had greater expression in cardiomyocytes than in cardiac fibroblasts $(p<0.01)$. Three expressed genes (in the red rectangle) were not different $(p>0.05)$. Three genes (in the green rectangle) were more expressed in cardiac fibroblasts than in cardiomyocytes $(p<0.01)$. Cell culture was done in six replications while quantitative polymerase chain reaction was done in three replications.

expression of Kcnql was specific to cardiac fibroblasts (24-fold) and muscle fibroblasts (20-fold) compared to skin fibroblasts. Wt1 was highly expressed only in cardiac fibroblasts (18-fold).

Most fibrotic gene expressions were similar among the three fibroblasts, except for Mmp9, Postn, Ctgf, and Thyl (Figure-4). The Mmp9 expression was highest in skin fibroblasts (25-fold) compared to muscle fibroblasts (16-fold) and cardiac fibroblasts $(1$-fold $)(p<0.01)$. The highest expressions of Postn (5-fold) and $\operatorname{Ctg} f$ (4-fold) were found in cardiac fibroblasts, while the highest expression of Thyl (3-fold) was seen in muscle fibroblasts.

\section{High serum concentration depressed cardiogenic gene expression}

The effect of serum concentration on cardiogenic gene expression of cardiac fibroblasts is shown in Figure-5. After adding a serum to a level of $20 \%$, the gene expressions of most cardiogenic genes (13 of 16 genes) tended to decrease, except 


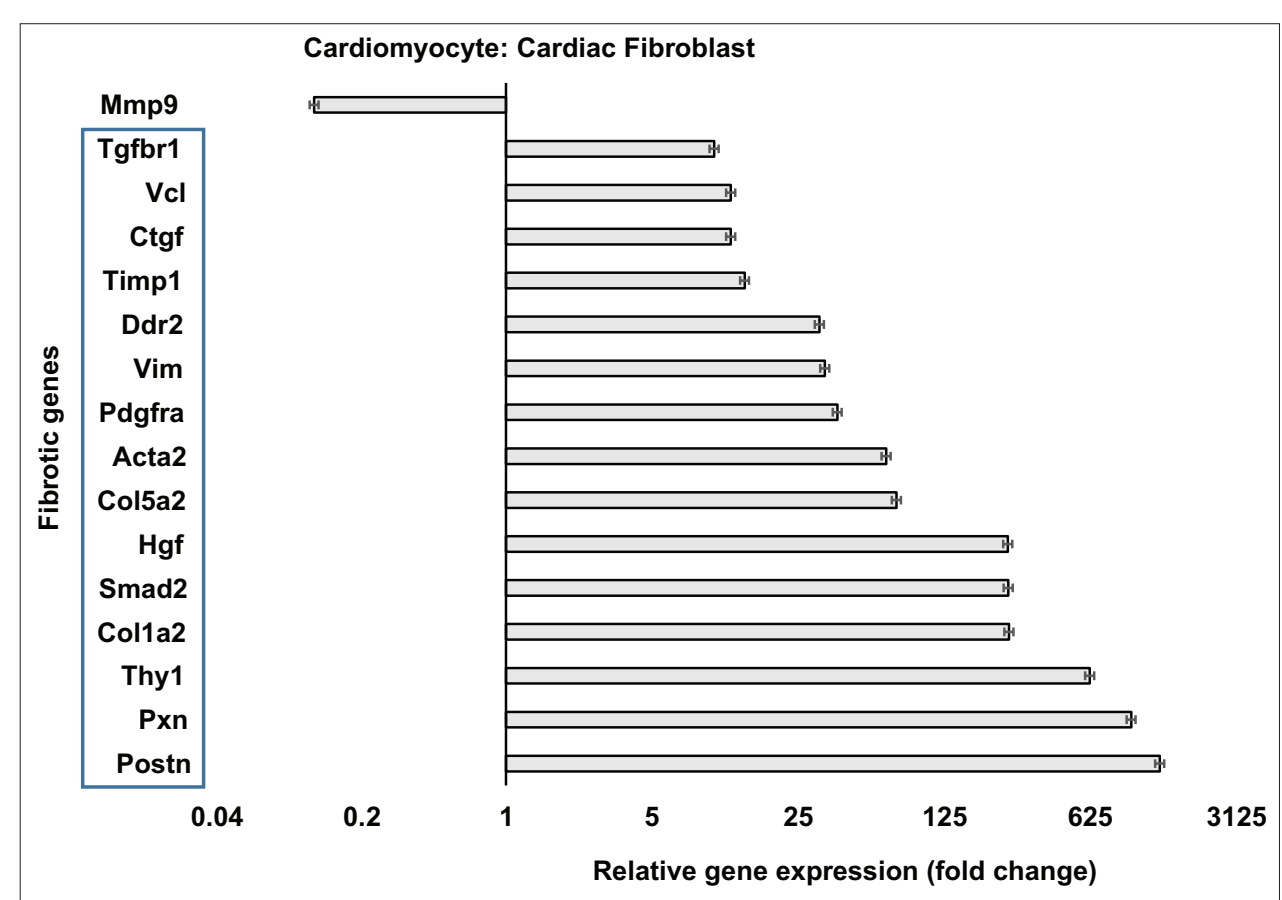

Figure-2: Fibrotic gene expression in cardiomyocytes compared to cardiac fibroblasts. Fifteen fibrotic genes (in the blue rectangle) had greater expression in cardiac fibroblasts than in cardiomyocytes $(p<0.01)$. Matrix metallopeptidase 9 expression was significantly higher in cardiomyocytes than in cardiac fibroblasts $(p<0.01)$. Cell culture was done in six replications while quantitative polymerase chain reaction was done in three replications.

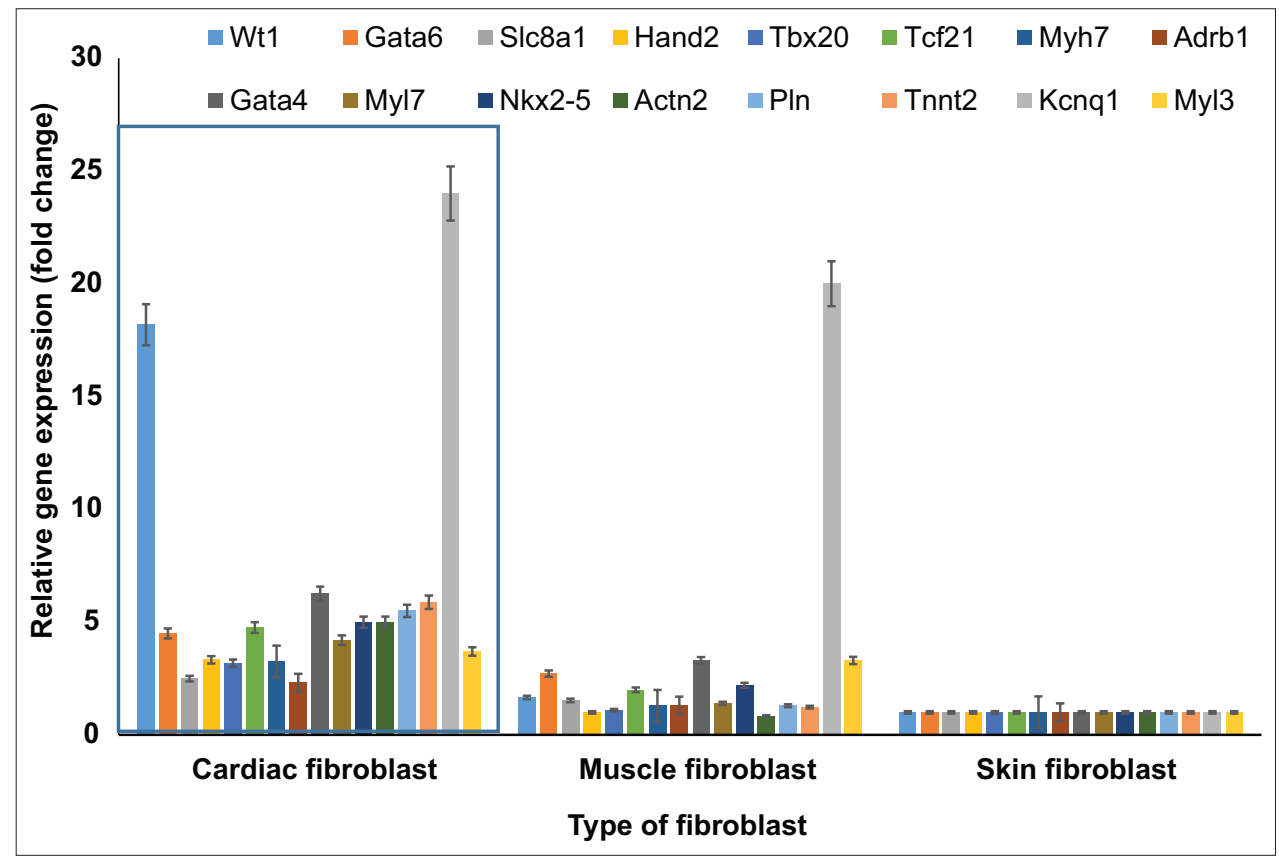

Figure-3: Comparative gene expressions of cardiogenic genes among cardiac, muscle, and skin fibroblasts. The gene expression of the skin fibroblasts was set to 1 , and the gene expressions of muscle and cardiac fibroblasts were calculated relative to skin fibroblasts. All cardiogenic genes had higher levels of expression $(p<0.01)$ in cardiac fibroblasts (in the rectangle) than in muscle and skin fibroblasts. The high expression of Wilms tumor 1 was very specific to cardiac fibroblast. Cell culture was done in six replications while quantitative polymerase chain reaction was done in three replications.

for Slc8a1, Gata6, and Hand2. The result of reducing the serum to $5 \%$ was variable. When we considered only $>2$-fold change of gene expression with a statistical significance $(\mathrm{p}<0.05), K c n q 1, P \ln , M y h 7$, $T b \times 20, T c f 21$, and $N k \times 2-5$ showed a difference (6 of 16 genes). Kcnq1 expression was undetectable after changing the serum concentration to both
$5 \%$ and $20 \%$, whereas $N k \times 2-5$ was unobtainable in $5 \%$ serum. Myh7 expression was very high (2.52fold) when cultured in 5\% serum but its expression was 0.43 -fold reduced when the serum media was switched to $20 \%$. The expression of $P \ln (0.40$-fold), Tbx20 (0.49-fold), and Tcf21 (0.49-fold) was lower in $20 \%$ serum. 


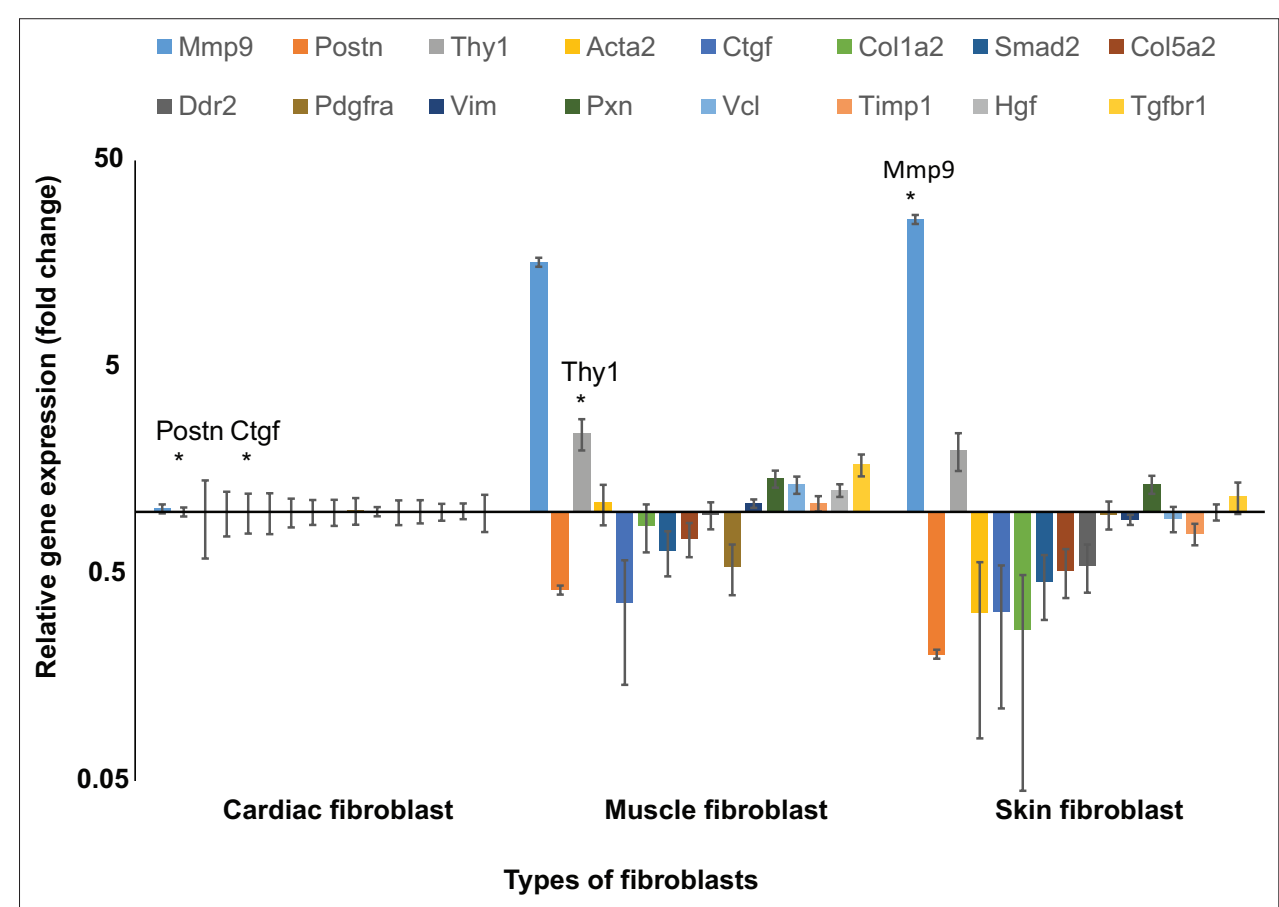

Figure-4: Relative gene expression of fibrotic genes compared among cardiac, muscle, and skin fibroblasts. The gene expressions of muscle and skin fibroblasts were calculated relative to cardiac fibroblasts (set to 1). *Represents the highest expression $(p<0.01)$. The highest expression of matrix metallopeptidase 9 was found in skin fibroblasts. Periostin and connective tissue growth factor were highly expressed in cardiac fibroblasts. Thy-1 cell surface antigen was the most highly expressed in muscle fibroblasts. Cell culture was done in six replications while quantitative polymerase chain reaction was done in three replications.

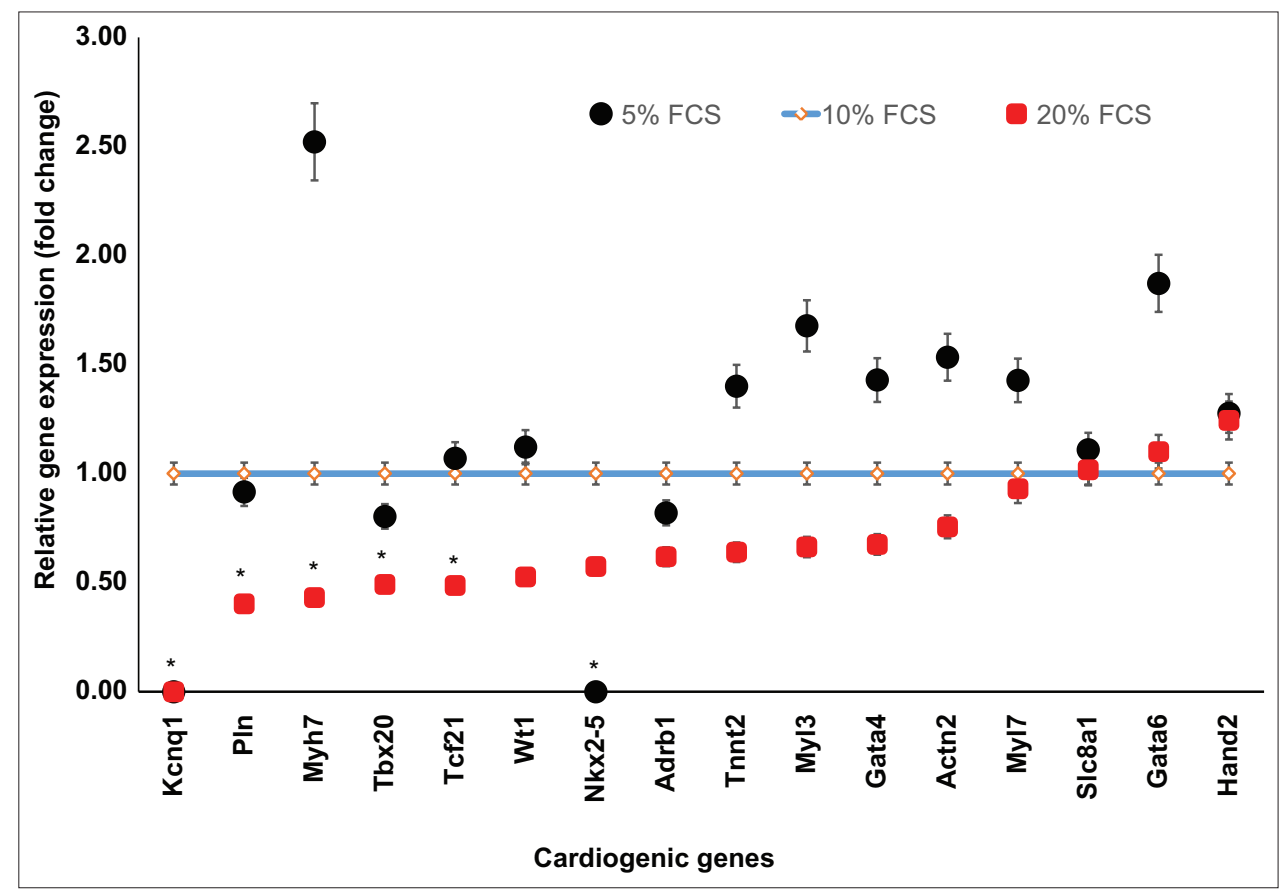

Figure-5: The effect of altered serum concentration in cultures of cardiac fibroblasts on cardiogenic gene expression. Gene expression of $10 \%$ fetal bovine serum culture (conventional culture) was set to 1 , and the gene expression of culture in $5 \%$ and $20 \%$ serum was calculated relative to conventional culture. The result of reducing the serum to $5 \%$ in culture was variable, but adding the serum to $20 \%$, tended to decrease gene expression of most cardiogenic genes. The expression of potassium voltage-gated channel subfamily $Q$ member 1, phospholamban, myosin heavy chain 7, T-Box Transcription Factor 20, transcription factor 21 , and NK2 homeobox 5 genes was significantly altered $(p<0.05)$. Cell culture was done in six replications while quantitative polymerase chain reaction was done in three replications.

Effect of serum concentration on fibrotic gene expression in cultured cardiac fibroblasts

The expression of the fibrotic genes in cardiac fibroblasts is illustrated in Figure-6. The fibrotic gene expression of cardiac fibroblasts was not affected by reducing the serum in the system to $5 \%$. Surprisingly, increasing serum concentration to $20 \%$ resulted in a reduction of most fibrotic genes' expressions, 


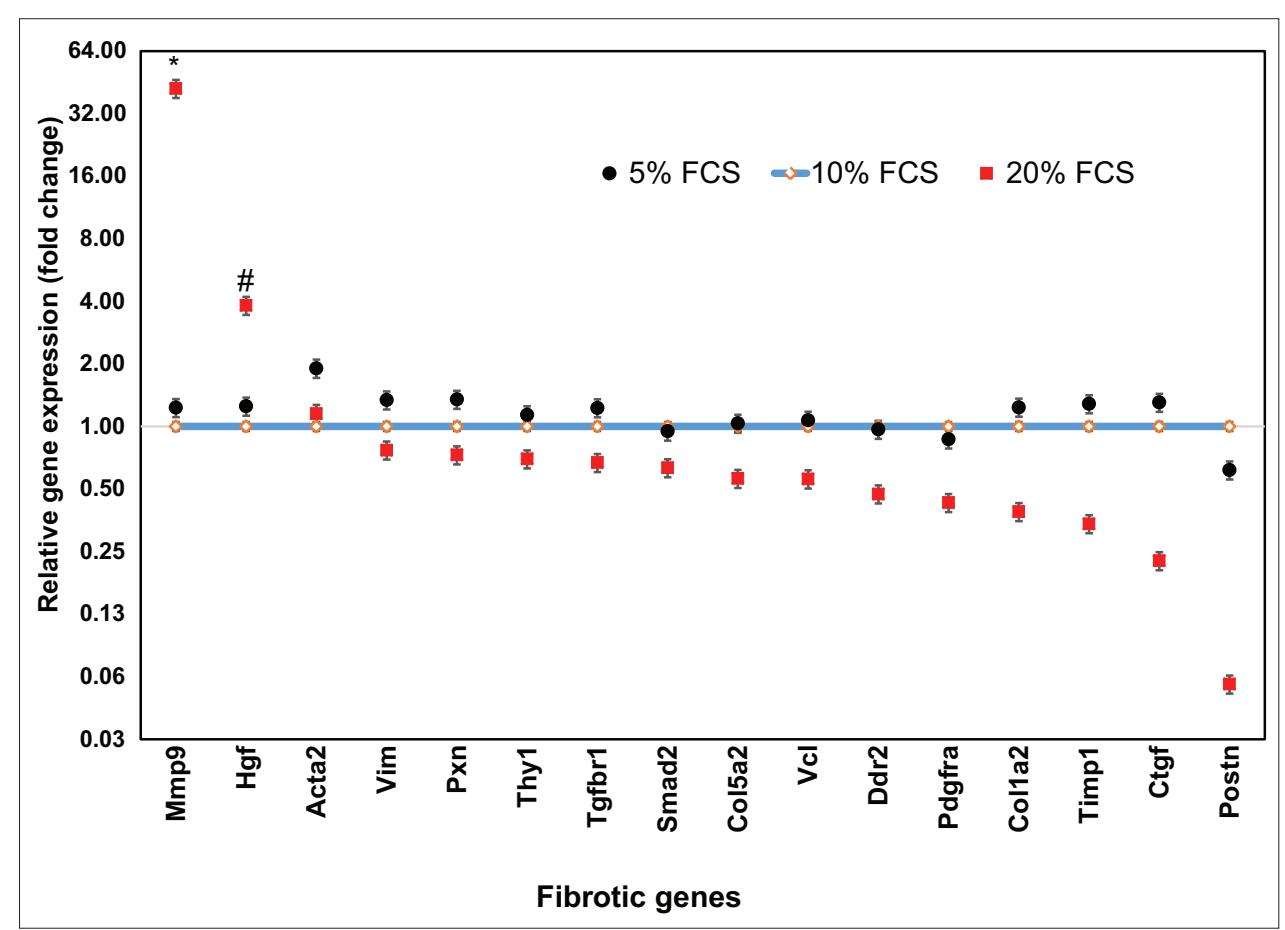

Figure-6: Effects of serum concentration on fibrotic gene expression. Gene expression of $10 \%$ fetal bovine serum culture (conventional culture) was set to 1 and the gene expression of culture in 5\% and $20 \%$ serum was calculated relative to conventional culture. Increasing serum concentration to $20 \%$ resulted in a reduction of most fibrotic gene expression, except for matrix metallopeptidase 9 and hepatocyte growth factor, which was significantly increased $(* p<0.01, \# p<0.05)$. Cell culture was done in six replications, while quantitative polymerase chain reaction was done in three replications.

except for $M m p 9$ and $H g f$, which were significantly increased 42.25-fold $(\mathrm{p}<0.01)$ and 2.82 -fold $(\mathrm{p}<0.05)$, respectively.

\section{In vitro model of cardiac ischemia and reperfusion}

It is well-known that an increase of $M m p 9$ expression is related to heart disease, particularly myocardium ischemia $[17,18]$ caused by coronary occlusion and resulting in cardiac cell starvation and injury. We mimicked blood blockage in vitro by removing serum in the culture medium for $24 \mathrm{~h}$ and investigated patterns of gene expression in five fibrotic genes (Mmp9, Postn, Hgf, Timp1, and Ctgf). The expression of genes in all three treatments (starvation and adding serum) was normalized by control culture (set to 1-fold). After the starvation, Mmp9 expression was reduced to undetectable levels. Its expression was, however, significantly elevated $(\mathrm{p}<0.05)$ after the serum of either $10 \%$ (2.89-fold) or $20 \%$ (4.59-fold) sera was added into the environment (Figure-7). $\mathrm{Hgf}$ expression was 3.45 -fold increased after the starvation, then substantially increased $(\mathrm{p}<0.05)$ after the addition of $10 \%$ (5.20-fold) or $20 \%$ (5.80-fold) sera to the system (Figure-7). Timpl expression was not affected after starvation, but its expression was significantly $(2.72$-fold $)$ reduced $(\mathrm{p}<0.05)$ when serum of up to $20 \%$ was added into the medium. This result suggested that the changes of Mmp9 and Timpl in cardiac fibroblasts were stimulated by increasing serum concentration, but not by starving, while $H g f$ expression could be induced by both starvation and elevated serum concentration.

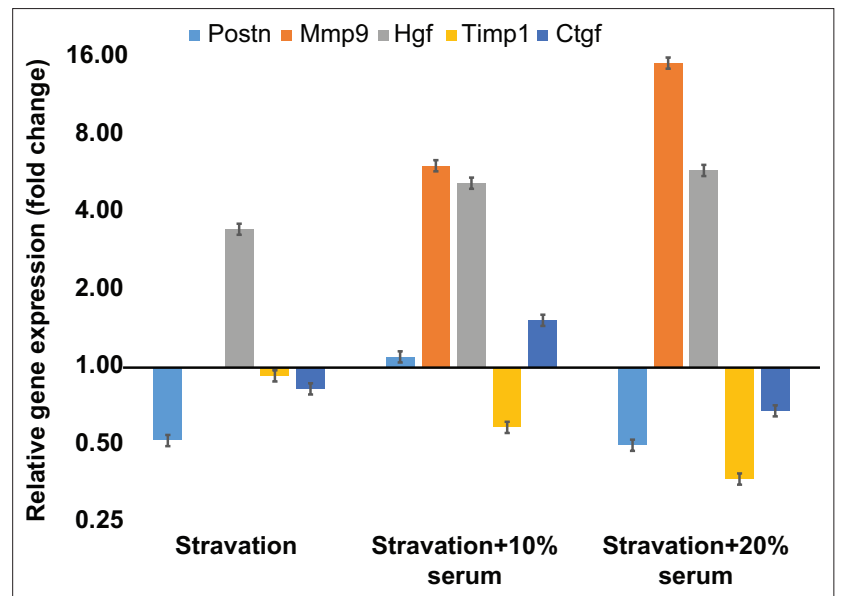

Figure-7: The effect of starvation and reintroduction of serum. Gene expression was calculated relative to a control culture $(10 \%$ serum $)$. Change of matrix metallopeptidase 9 and tissue inhibitor of metalloproteinase 1 expression in cardiac fibroblasts was statistically altered $(p<0.05)$ by increased serum concentration, whereas hepatocyte growth factor expression was significantly altered $(p<0.05)$ by both starvation and elevated serum concentration. Cell culture was done in six replications, while quantitative polymerase chain reaction was done in three replications.

\section{Comparative gene expression among fibroblasts from different tissues}

We investigated whether this effect of high serum concentration was specific to cardiac fibroblasts, with no effect on other fibroblasts (e.g., skin and muscle fibroblasts). The gene expression of each type of fibroblast was calculated relative to conventional culture $(10 \%$ serum). In $20 \%$ serum culture, 
each type of fibroblast behaved differently (Figure-8). Cardiac fibroblasts were found to be the most sensitive to the increased concentration of serum. Although the expressions of most of the fibrotic genes from cardiac fibroblasts were reduced, $M m p 9$ and $H g f$ expressions were elevated approximately 40-fold $(p<0.01)$ and 3-fold $(p<0.05)$, respectively. Many fibrotic genes from muscle fibroblasts, particularly Tgfbr, Ctgf, and Postn, responded similarly to those from cardiac fibroblasts. In this study, we detected no effect of a high serum concentration on the gene expression of skin fibroblasts.

\section{Discussion}

The present study has revealed that rat cardiac fibroblasts express both cardiogenic and fibrotic genes, but their expression patterns were different from cardiomyocytes and fibroblasts localized in other tissues. The expressions of most cardiogenic genes in cardiac fibroblasts were lower than those in cardiomyocytes. Notably, cardiac fibroblasts were more sensitive to a high serum concentration, compared to other fibroblasts. This resulted in notable changes in cardiogenic and fibrotic gene expression.

The expressions of cardiogenic genes such as Slc8a1, Gata6, and $W t 1$ in rat cardiac fibroblasts were significantly higher than in cardiomyocytes. This finding is consistent with a previous study [10], where higher expressions of Gata6 and Wt1 were observed in mouse cardiac fibroblasts, compared to the heart tissue.
Considering a comparison of the fibrotic gene expression among the three types of fibroblasts, the present study has demonstrated that the $M m p 9$ expression in cardiac fibroblasts was much lower than that in other fibroblasts and cardiomyocytes. This low level of Mmp9 expression was previously reported in rats and humans $[19,20]$. Surprisingly, increasing serum concentration induced an extremely high level of expression of $M m p 9$ in rat cardiac fibroblasts. It is well known that Mmp9 plays a key role in the development of cardiovascular diseases as well as cardiac remodeling by altering ECM, fibroblast migration, collagen and cytokine production, and stimulating cell differentiation [18,21]. Increasing $M m p 9$ expression in cardiac fibroblasts is a clinically detrimental sign as it is associated with matrix changes caused by heart disease [22]. Mmp9 is also used as a marker to assess the severity of cardiovascular diseases $[18,21]$ - an increased level indicates a poor prognosis. In myocardial ischemia, the increased levels of Mmp 9 protein in the serum are related to secretion of white blood cells such as neutrophils and macrophages [23,24]. Although cardiac fibroblasts are not a primary source for $\mathrm{Mmp} 9$ production [23], moderately increased expression of Mmp9 can, however, be observed in experimentally-induced myocardial ischemia model studies using hypoxia, oxidative stress, and cytokines such as interleukin-1 $\beta$ and tumor necrosis factor-alpha [20,25-27]. Nonetheless, the gene/protein expression in cardiac fibroblasts during myocardial ischemia/reperfusion is currently poorly understood. The majority of studies

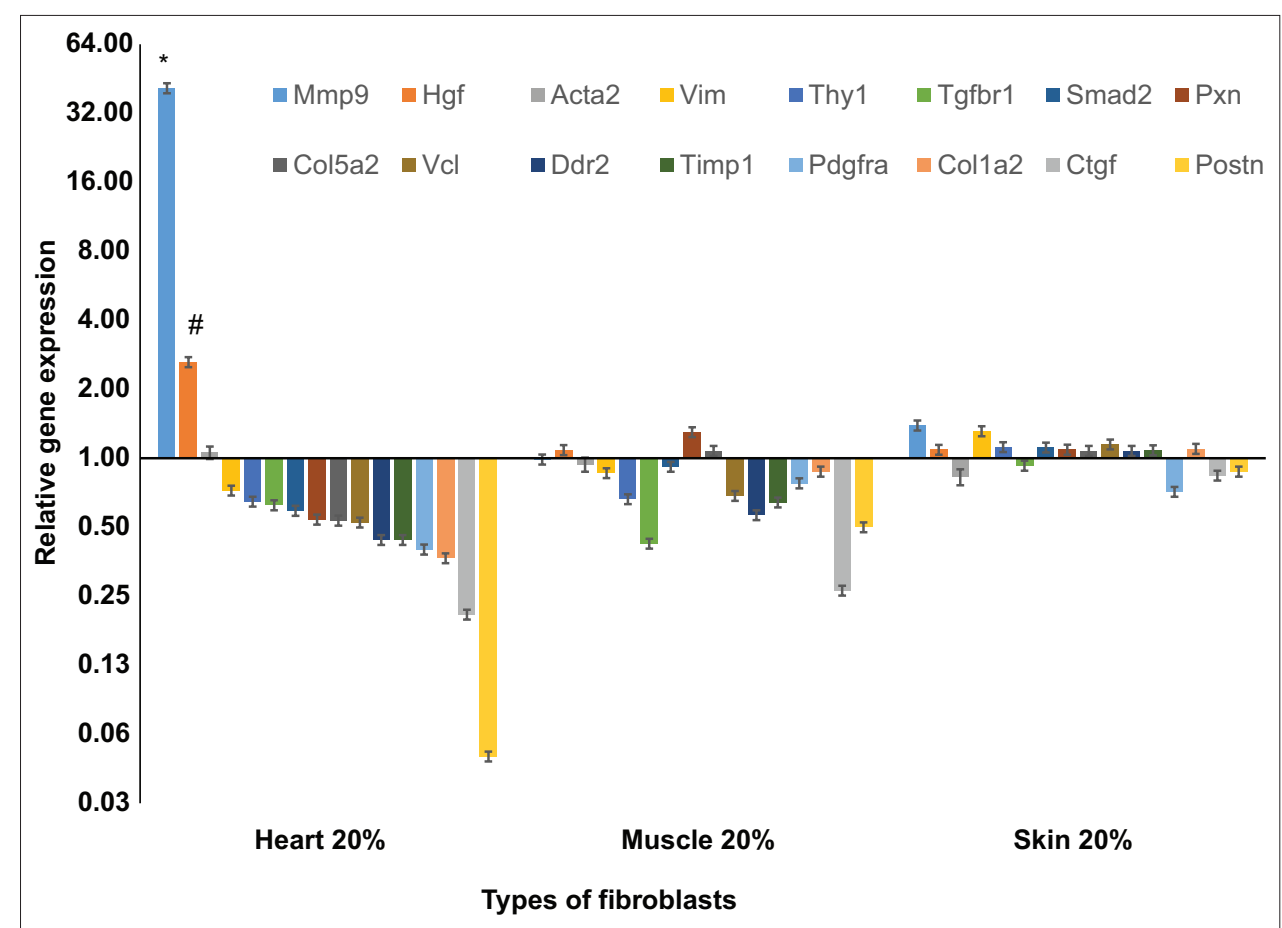

Figure-8: Fibrotic gene expression in 20\% serum culture compared among three types of fibroblasts. The expression was calculated relative to $10 \%$ serum culture (control) and gene expression was relative to control culture (10\% serum). Cardiac fibroblasts were more sensitive to increased serum concentration than skin and muscle fibroblasts. *The expression of most fibrotic genes from cardiac fibroblasts was reduced. Matrix metallopeptidase 9 and hepatocyte growth factor expression was significantly elevated $(* p<0.01$ and $\# p<0.05)$. Cell culture was done in six replications, while quantitative polymerase chain reaction was done in three replications. 
use an in vitro culture to investigate the physiology and molecular functions of cardiac fibroblasts [28]. In the present study, we used serum starvation/reduction and then added more serum to simulate myocardial ischemia/reperfusion phenomenon. Our results suggested that an introduction of the serum, but not after starvation, stimulated the high expression of Mmp9. This finding suggests a potential function of myocardial reperfusion being a key to induce $M m p 9$ expression in survived fibroblasts and thus causing a rapid disease progression. In another study, one of the Mmp family proteins, Mmp1, is also found to increase after $20 \%$ of serum was added into the medium of human cardiac fibroblasts [29].

Timpl is a natural inhibitor of $M m p 9$ [30], and it plays a regulatory role in post-myocardial ischemia by accelerating myocardial remodeling [31]. Both upregulation of Timpl and downregulation of $\mathrm{Mmp} 9$ in cardiac fibroblasts have been proved to preserve cardiac functions and inhibit fibrosis in cardiomyopathy $[32,33]$. In this study, Timp1 expression was not affected by a low concentration or absence of serum in the culture, but increased serum concentration could reduce the expression of Timp1. In a previous study, serum starvation was shown to stimulate other genes in the Mmp and Timp families, including Mmp2 and Timp2 [34].

As for $H g f$, the gene expression was elevated both after starvation and after increasing the serum concentration in the culture to $20 \%$. This result is similar to the previous in vivo studies $[35,36]$. The serum $H g f$ in these studies was heightened following acute myocardial ischemia/reperfusion. $\mathrm{Hgf}$ acts as a cardioprotective factor. The administration of $H g f$ protein was shown to reduce infarct size and promoted cardiac performance in acute ischemia/reperfusion in rats and dogs [36,37]. In contrast, a blockade of endogenous $H g f$ increases infarct size and mortality [37]. These cardioprotective effects of $H g f$ are proposed to be related to its angiogenic, anti-apoptotic, and anti-TGF- $\beta 1$ pathways $[37,38]$. However, in another model of myocardial ischemia where cardiac fibroblasts were cultured in a hypoxic condition, $H g f$ was decreased [26].

It has been shown that high expression of Ctgf and Postn genes is important for heart remodeling after myocardial ischemia [39-43]. The function of Ctgf involves many cellular processes underlying fibrosis, such as cell proliferation, adhesion, migration, and the synthesis of ECM [41], while Postn primarily relates to cell adhesion and interactions with ECM [43]. The results from the present study illustrated that the levels of $\operatorname{Ctg} f$ and Potn were diminished after the serum withdrawal. Their expressions improved when the concentration of the serum was shifted to $10 \%$, and declined after exposing to $20 \%$ serum. This phenomenon highlights the fact that ischemia can be responsible for a reduction of $\operatorname{Ctg} f$ and Postn expression in cardiac fibroblasts, but proper reperfusion can restore the expression of $\operatorname{Ctg} f$ and Postn.
While the effect of starvation on cultured cardiac fibroblasts has been commonly used to simulate myocardial ischemia [41,44-46], there has been only a limited number of studies simulating reperfusion injuries through an increased serum concentration in culture [29]. The strategy of using starvation and then introducing the serum can be useful to mimic myocardial ischemia and reperfusion injuries; however, actual cases of myocardial ischemia do not involve only nutrients, hormones, and proteins in serum but also a depleted oxygen condition. In most serum starvation studies, including the present one, oxygen persists in the system. This makes the model an imperfect simulation of myocardial ischemia/reperfusion in vitro. The culture of cardiac fibroblasts with hypoxia conditions has also been used as an alternative model for myocardial ischemia, and it produced the opposite result to the serum starvation technique. For instance, $M m p 9$ expression was elevated, whereas $H g f$ expression was decreased [26].

\section{Conclusion}

We propose that rat cardiac fibroblasts differ from other fibroblasts, in terms of their gene expression and sensitivity to serum concentration changes. An increased serum concentration, but not a reduced one, can substantially stimulate the expression of Mmp9 and Hgf, while inhibiting Timpl, Ctgf, and Postn, suggesting that cardiac fibrosis may be stimulated by overwhelming of blood reperfusion rather than ischemia. The strategy of applying the starvation technique followed by a re-introduction of the serum could be methodologically useful in an in vitro study of the changes in blood flow to cardiac fibroblasts, which commonly occurs in myocardial ischemia/ reperfusion cases.

Future studies should focus on the development of strategies to manipulate cardiac fibroblast to function properly. Specifically, seeking for new cardioprotective drugs that control fibroblast gene expression or optimal blood flow during reperfusion injuries.

\section{Authors' Contributions}

TW performed the experiment in cell culture and PCR while KT collected cardiomyocytes. KT and TW wrote manuscript and analyzed the data. Both authors read and approved the final manuscript.

\section{Acknowledgments}

This project was mainly supported by Mahidol University Research grant (2552) and partially supported by British Council-Newton Fund (Research Link: 216425505) and the New Strategic Research (P2P) project (phase 2), Walailak University (iCGS2019-135) to TW, and Thailand Research Fund grant TRG5680085 to KT. We would like to Thank Dr. Sari Pennings from the University of Edinburgh for valuable comment on this project and the manuscript. The English proofreading was done by Mr. Matthew Colin Morrill, the lecturer of Walailak University. 


\section{Competing Interests} interests.

The authors declare that they have no competing

\section{Publisher's Note}

Veterinary World remains neutral with regard to jurisdictional claims in published institutional affiliation.

\section{References}

1. Humeres, C. and Frangogiannis, N.G. (2019) Fibroblasts in the infarcted, remodeling, and failing heart. J. Am. Coll. Cardiol. Basic Transl. Sci., 4(3): 449-467.

2. Tallquist, M.D. and Molkentin, J.D. (2017) Redefining the identity of cardiac fibroblasts. Nat. Rev. Cardiol., 14(8): 484-491.

3. Bergmann, O., Zdunek, S., Felker, A., Salehpour, M., Alkass, K., Bernard, S., Sjostrom, S.L., Szewczykowska, M., Jackowska, T., Dos Remedios, C., Malm, T., Andrä, M., Jashari, R., Nyengaard, J.R., Possnert, G., Jovinge, S., Druid, H. and Frisén, J. (2015) Dynamics of cell generation and turnover in the human heart. Cell, 161(7): 1566-1575.

4. Ivey, M.J. and Tallquist, M.D. (2016) Defining the cardiac fibroblast. Circ. J., 80(11): 2269-2276.

5. Furtado, M.B., Nim, H.T., Boyd, S.E. and Rosenthal, N.A. (2016) View from the heart: Cardiac fibroblasts in development, scarring and regeneration. Development, 143(3): 387-397.

6. Herum, K.M., Choppe, J., Kumar, A., Engler, A.J. and McCulloch, A.D. (2017) Mechanical regulation of cardiac fibroblast profibrotic phenotypes. Mol. Biol. Cell, 28(14): 1871-1882.

7. Ma, Z.G., Yuan, Y.P., Wu, H.M., Zhang, X. and Tang, Q.Z. (2018) Cardiac fibrosis: New insights into the pathogenesis. Int. J. Biol. Sci., 14(12): 1645-1657.

8. Tian, J., An, X. and Niu, L. (2017) Myocardial fibrosis in congenital and pediatric heart disease. Exp. Ther. Med., 13(5): 1660-1664.

9. Dick, M.K., Miao, J.H. and Limaiem, F. (2019) Histology, fibroblast. In: Stat Pearls. Stat Pearls Publishing, Treasure Island, FL.

10. Furtado, M.B., Costa, M.W., Pranoto, E.A., Salimova, E., Pinto, A.R., Lam, N.T., Park, A., Snider, P., Chandran, A., Harvey, R.P., Boyd, R., Conway, S.J., Pearson, J., Kaye, D.M. and Rosenthal, N.A. (2014) Cardiogenic genes expressed in cardiac fibroblasts contribute to heart development and repair. Cir. Res., 114(9): 1422-1434.

11. Furtado, M.B., Nim, H.T., Gould, J.A., Costa, M.W., Rosenthal, N.A. and Boyd, S.E. (2014) Microarray profiling to analyse adult cardiac fibroblast identity. Genom. Data, 2: 345-350.

12. Nakahara, T., Tanimoto, T., Petrov, A.D., Ishikawa, K., Strauss, H.W. and Narula, J. (2018) Rat model of cardiotoxic drug-induced cardiomyopathy. In: Ishikawa, K., editor. Experimental Models of Cardiovascular Diseases. Methods in Molecular Biology. Vol. 1816. Humana Press, New York, USA.

13. Meléndez, G.C., Manteufel, E.J., Dehlin, H.M., Register, T.C. and Levick, S.P. (2015) Non-human primate and rat cardiac fibroblasts show similar extracellular matrix-related and cellular adhesion gene responses to substance P. Heart Lung Circ., 24(4): 395-403.

14. O'Connell, T.D., Rodrigo, M.C. and Simpson, P.C. (2007) Isolation and culture of adult mouse cardiac myocytes. Methods Mol. Bio., 357: 271-296.

15. Watchrarat, K., Korchunjit, W., Buranasinsup, S., Taylor, J., Ritruechai, P. and Wongtawan, T. (2017) MEM $\alpha$ promotes cell proliferation and expression of bone marrow derived equine mesenchymal stem cell gene markers but depresses differentiation gene markers. J. Equine Vet. Sci., 50: 8-14.

16. Vandesompele, J., De Preter, K., Pattyn, F., Poppe, B., Van Roy, N., De Paepe, A. and Speleman, F. (2002) Accurate normalization of real-time quantitative RT-PCR data by geometric averaging of multiple internal control genes. Genome Biol., 3: research0034.1.

17. Yabluchanskiy, A., Ma, Y., Iyer, R.P., Hall, M.E. and Lindsey, M.L. (2013) Matrix metalloproteinase-9: Many shades of function in cardiovascular disease. Physiology (Bethesda), 28(6): 391-403.

18. Halade, G.V., Jin, Y.F. and Lindsey, M.L. (2013) Matrix metalloproteinase (MMP)-9: A proximal biomarker for cardiac remodeling and a distal biomarker for inflammation. Pharmacol. Ther., 139(1): 32-40.

19. Lindner, D., Zietsch, C., Becher, P.M., Schulze, K., Schultheiss, H.P., Tschöpe, C. and Westermann, D. (2012) Differential expression of matrix metalloproteases in human fibroblasts with different origins. Biochem. Res. Int., 2012: 875742.

20. Xie, Z., Singh, M. and Singh, K. (2004) Differential regulation of matrix metalloproteinase-2 and -9 expression and activity in adult rat cardiac fibroblasts in response to interleukin-1beta. J. Biol. Chem., 279(38): 39513-39513.

21. Phatharajaree, W., Phrommintikul, A. and Chattipakorn, N. (2007) Matrix metalloproteinases and myocardial infarction. Can. J. Cardiol., 23(9): 727-733.

22. K-Raman, P., Purushothaman, M., Adams, D.H., Krishnan, P., Kini, A., Sharma, S.K., Fuster, V. and Moreno, P.R. (2014) Increased fibroblast activation protein and matrix metalloproteinase-9 expression are associated with altered extra-cellular matrix changes in barlow's disease compared to fibro elastic deficiency in mitral valve degenerative disease-implication in disease progression. Circulation, 130(2): A17274.

23. Iyer, R.P., Jung, M. and Lindsey, M.L. (2016) MMP-9 signaling in the left ventricle following myocardial infarction. Am. J. Physiol. Heart Circ. Physiol., 311: H190-H198.

24. Lindsey, M.L. (2018) Assigning matrix metalloproteinase roles in ischaemic cardiac remodelling. Nat. Rev. Cardio., 15(8): 471-479.

25. Brown, R.D., Jones, G.M., Laird, R.E., Hudson, P. and Long, C.S. (2007) Cytokines regulate matrix metalloproteinases and migration in cardiac fibroblasts. Biochem. Biophys. Res. Commun., 362(1): 200-205.

26. Gao, Q., Guo, M., Zeng, W., Wang, Y., Yang, L., Pang, X., Li, H., Suo, Y., Jiang, X. and Yu, C. (2015) Matrix metalloproteinase 9 secreted by hypoxia cardiac fibroblasts triggers cardiac stem cell migration in vitro. Stem Cells Int., 2015: 836390.

27. Siwik, D.A., Pagano, P.J. and Colucci, W.S. (2001) Oxidative stress regulates collagen synthesis and matrix metalloproteinase activity in cardiac fibroblasts. Am. J. Physiol. Cell Physiol., 280(1): C53-C60.

28. Zhou, Y., Richards, A.M. and Wang, P. (2017) Characterization and standardization of cultured cardiac fibroblasts for ex vivo models of heart fibrosis and heart ischemia. Tissue Eng. Part C Methods, 23(7): 422-433.

29. Tyagi, S.C., Kumar, S. and Glover, G. (1995) Induction of tissue inhibitor and matrix metalloproteinase by serum in human heart-derived fibroblast and endomyocardial endothelial cells. J. Cell. Biochem., 58(3): 360-371.

30. Niño, M.E., Serrano, S.E., Niño, D.C., McCosham, D.M., Cardenas, M.E., Villareal, V.P., Lopez, M., Pazin-Filho, A., Jaimes, F.A., Cunha, F., Schulz, R. and Torres-Dueñas, D. (2017) TIMP1 and MMP9 are predictors of mortality in septic patients in the emergency department and intensive care unit unlike MMP9/TIMP1 ratio: Multivariate model. PLoS One, 12(2): e 0171191.

31. Ikonomidis, J.S., Hendrick, J.W., Parkhurst, A.M., Herron, A.R., Escobar, P.G., Dowdy, K.B., Stroud, R.E., Hapke, E., Zile, M.R. and Spinale, F.G. (2005) Accelerated LV remodeling after myocardial infarction 
in TIMP-1-deficient mice: Effects of exogenous MMP inhibition. Am. J. Physiol. Heart Circ. Physiol., 288(1): H149-H158.

32. Jayasankar, V., Woo, Y.J., Bish, L.T., Pirolli, T.J., Berry, M.F., Burdick, J., Bhalla, R.C., Sharma, R.V., Gardner, T.J. and Sweeney, H.L. (2004) Inhibition of matrix metalloproteinase activity by TIMP-1 gene transfer effectively treats ischemic cardiomyopathy. Circulation, 110(1): II180-II186.

33. Kinoshita, T., Ishikawa, Y.,Arita, M.,Akishima-Fukasawa,Y., Fujita, K., Inomata, N., Suzuki, T., Namiki, A., Mikami, T., Ikeda, T., Yamazaki, J., Ishii, T. and Akasaka, Y. (2014) Antifibrotic response of cardiac fibroblasts in hypertensive hearts through enhanced TIMP-1 expression by basic fibroblast growth factor. Cardiovasc. Pathol., 23(2): 92-100.

34. Leicht, M., Briest, W., Holzl, A. and Zimmer, H.G. (2001) Serum depletion induces cell loss of rat cardiac fibroblasts and increased expression of extracellular matrix proteins in surviving cells. Cardiovasc. Res., 52(3): 429-437.

35. Zhu, Y., Hojo, Y., Ikeda, U. and Shimada, K. (2000) Production of hepatocyte growth factor during acute myocardial infarction. Heart, 83(4): 450-455.

36. Nakamura, T., Mizuno, S., Matsumoto, K., Sawa, Y., Matsuda, H. and Nakamura, T. (2000) Myocardial protection from ischemia/reperfusion injury by endogenous and exogenous HGF. J. Clin. Invest., 106(12): 1511-1519.

37. Jin, H., Wyss, J.M., Yang, R. and Schwall, R. (2004) The therapeutic potential of hepatocyte growth factor for myocardial infarction and heart failure. Curr. Pharm. Des., 10(20): 2525-2533.

38. Yi, X., Li, X., Zhou, Y., Ren, S., Wan, W., Feng, G. and Jiang, $X$. (2014) Hepatocyte growth factor regulates the TGF$\beta 1$-induced proliferation, differentiation and secretory function of cardiac fibroblasts. Int. J. Mol. Med., 34(2): 381-390.

39. Gravning, J., Orn, S., Kaasboll, O.J., Martinov, V.N., Manhenke, C., Dickstein, K., Edvardsen, T., Attramadal, H. and Ahmed, M.S. (2012) Myocardial connective tissue growth factor (CCN2/CTGF) attenuates left ventricular remodeling after myocardial infarction. PLoS One, 7(12): e52120.

40. Taniyama, Y., Katsuragi, N., Sanada, F., Azuma, J., Iekushi, K., Koibuchi, N., Okayama, K., Ikeda-Iwabu, Y., Muratsu, J., Otsu, R., Rakugi, H. and Morishita, R. (2016) Selective blockade of periostin exon 17 preserves cardiac performance in acute myocardial infarction. Hypertension, 67(2): 356-361.

41. Wong, C.K.S., Falkenham, A., Myers, T. and Légaré, J.F. (2018) Connective tissue growth factor expression after angiotensin II exposure is dependent on transforming growth factor- $\beta$ signaling via the canonical SMAD-dependent pathway in hypertensive induced myocardial fibrosis. J. Renin Angiotensin Aldosterone Syst., 19(1): 1470320318759358.

42. Lipson, K.E., Wong, C., Teng, Y. and Spong, S. (2012) CTGF is a central mediator of tissue remodeling and fibrosis and its inhibition can reverse the process of fibrosis. Fibrogenesis Tissue Repair, 5(1): S24.

43. Kaur, H., Takefuji, M., Ngai, C.Y., Carvalho, J., Bayer, J., Wietelmann, A., Poetsch, A., Hoelper, S., Conway, S.J., Möllmann, H., Looso, M., Troidl, C., Offermanns, S. and Wettschureck, N. (2016) Targeted ablation of periostin-expressing activated fibroblasts prevents adverse cardiac remodeling in mice. Circ. Res., 118(12): 1906-1917.

44. Kvandová, M., Majzúnová, M. and Dovinová, I. (2016) The role of PPARgamma in cardiovascular diseases. Physiol. Res., 65(3): S343-S363.

45. Cowling, R.T., Park, J.I., Sotimehin, A.E. and Greenberg, B.H. (2017) Ascorbate starvation alters endoplasmic reticulum-resident enzymes in cardiac fibroblasts, priming them for increased procollagen secretion. J. Mol. Cell Cardiol., 113: 1-8.

46. Li, Y.L., Hao, W.J., Chen, B.Y., Chen, J. and Li, G.Q. (2018) Cardiac fibroblast-specific activating transcription factor 3 promotes myocardial repair after myocardial infarction. Chin. Med. J. (Engl)., 131(19): 2302-2309. 